\title{
Research on the Innovation Path of University Physical Education under the Background of Quality Education
}

\author{
Yuanyuan Liu \\ Department of Physical Education, Chengdu University of Information Technology, Chengdu, Sichuan, China, \\ 610225
}

Keywords: quality education; physical education; innovation path

\begin{abstract}
The development of the times calls for cultivating the overall quality of students. The current quality education has become the background of current education, which requires that innovation and reform must be carried out in the process of education in order to change the traditional notion that is not conducive to cultivating students' overall quality. Therefore, it is necessary to explore innovation path in university teaching of physical education in the context of quality education. This paper discusses the problems faced by the university physical education innovation under the background of quality education, and points out the effective path of adapting quality education and carrying out university physical education innovation.
\end{abstract}

\section{Introduction}

To develop physical education and improve students' physical quality in the university education, it is necessary to strengthen the degree of emphasis on sports. For the current needs of the training of talents, the mission of higher education institutions themselves has become even more significant [1]. In the process of continuous development of employment demand in the current society, universities and colleges should pay more attention to whether the students' overall quality has been effectively promoted and developed in the actual participation in the education process. Only in this way can they really become available to the current society. In the current higher education system, physical education is a very important part of it. Facing with the new demands for quality education in the new era, in the process of developing physical education it should integrate students' physical education with their growth and development through effective innovation and reform. And in the process of participating in physical education, students are fully educated and developed in their own qualities.

\section{The Connotation of Physical Education Innovation in Colleges and Universities}

\subsection{Adaptive innovation.}

In the process to launch of the sports education innovation, it should meet the actual conditions of different students and improve the pertinence of physical education work. Combining each student's actual situation with effective physical education activities can make physical education activities more effective. In the process of innovating sports education, it should be adjusted around the actual needs and hobbies of the students at the current stage so that the students themselves have stronger enthusiasm for participation and enthusiasm for participation. In addition, from the perspective of adaptive innovation, the development of physical education innovation should better adapt to the development trend of the current social era. For example, in sports education, some current sports news and sports theories can be introduced to make the work of physical education more distinctive, and students can also realize that the learning of sports knowledge is in actual life, and only in this way, the student's own motivation for participation can be better strengthened. Besides, effective adaptation is also a necessary basis for the current physical education to be reasonable and effective. 


\subsection{Continuous innovation.}

For the development of physical education in institutions of higher learning, to achieve effective innovation, it should improve the continuity of innovation from a continuous perspective, so that the quality of the students' own quality training would be more effective. In the process of launching relevant innovation work, we should analyze the rationality of the content of physical education at the current stage from a long-term perspective, and through in-depth research and analysis, to help the current physical education have stronger sustainability and could better enable students' grow and develop. In the course of the education of physical education, colleges and universities should also fully study and analyze the actual neural characteristics of the students, and improve and develop the quality of all aspects in the process of participating in physical education. It should also attach importance to the guidance of students' ideas and concepts in the process of actual education innovation, which allow students to form the concept of lifelong sports, and provide a good foundation for their future growth and development. Continuous innovation is a new idea and direction of the current sports education innovation and it is also a necessary prerequisite for guaranteeing the effectiveness of innovation work, which should be given enough attention and attention.

\subsection{Comprehensive innovation.}

In the process of sports teaching and innovation, we should ensure that its teaching activities can better cover the development of students' overall quality. Under the concept of quality education, the development of physical education should not only cultivate students' knowledge of movement and motor skills, but also allow students to form good exercise habits, and could get the all-round growth and development of our willpower in the process of participating in physical education. Only by guaranteeing the comprehensiveness of innovation, can the development of physical education work better meet the training needs of students' comprehensive qualities, which is also an important embodiment of the concept of quality education in the new era.

\section{The Problems in the Physical Education Innovation in Colleges and Universities}

\subsection{Emphasizing theoretical training and ignoring practical education.}

In the process of actual innovative education, traditional concepts have not been thoroughly reformed. In the process of teaching, the teacher's own ideas are not advanced enough, theoretical teaching still occupies a large part, and they pay more attention to the cultivation of students' knowledge and skills in physical education. It does not focus on the guidance and development of students' willpower quality, which limits the students' thinking and leads students to master the theory, and difficult to carry out practical operations, which is not conducive to the cultivation of students' overall quality.

\subsection{Teachers' innovative ability needs to be improved.}

Teachers, as the guides of physical education reform activities, are very important in the overall physical education reform activities. In the specific physical education reforms, the importance of teachers' professional standards is even more prominent. College PE teachers lack the practical ideas and practical abilities of the idea of quality education in PE education [2]. They are more than just purely a job and do not devote themselves to the promotion of their own sports level. By observing the reform of university physical education teaching, we can see that a considerable number of physical teachers also have deficiencies in the relevant professional knowledge reserves. In the course of the reform of physical education, the University PE teachers are not clear, lack of effective methods, or apply the traditional instillation method of physical education in dealing with the reform of the heuristic teaching of physical education and the reform of the task-based PE teaching. On the whole, the classroom is very boring and the students are very easy to get tired of the mood. 


\subsection{Teachers lack enthusiasm for quality education.}

Most college sports teachers don't have much enthusiasm for the practice and application of quality education in physical education reform, and more of them focus on sports skills education. The physical education failed to combine with the interests of college students, failed to combine with physical and mental health, and failed to integrate well with cultural heritage. PE teachers did not successfully stimulate the enthusiasm of students in physical education reform activities, which led to low participation of students in the overall classroom and the lack of practical and effective learning behavior. At the micro level, there are loopholes in the school's management mechanism, which will inevitably bring negative impact to the physical education reform practice at the macro level. This kind of physical education reform approach is even more inconsistent in the context of quality education theory that focuses on practical ability, which is not only unfavorable to the progress and development of college physical education teaching reform, but also very unfavorable to the long-term development of individual students.

\section{Innovation Path of Physical Education Teaching in Colleges and Universities}

\subsection{Innovation in ideology.}

In the process of carrying out the reform of physical education in Colleges and universities, we should position the starting point of innovation work in the innovation of ideology. Only from the ideological awareness of the important needs of the current innovation of sports education, and ideological awareness and understanding of the current stage of quality education for the orientation and goal of physical education work, so that the follow-up of the development of sports education innovation can have a better support and guarantee [3]. In the course of the actual teaching, the innovation of the sports education should pay more attention to the positive role of the physical education work for the students' growth, to have the students participate in the sports education, and get the development of the sports knowledge, and so on. Colleges and universities should also actively promote the development of relevant teaching and research work, and better understand the needs of physical education in the new era. At present, in the course of sports education, we should carry out a hierarchical teaching method, fully understand the actual situation of different students, combine the shortcomings and problems of their existence, introduce more scientific education means, and build a good foundation for physical education for them. In the course of daily education, we should combine the characteristics and needs of higher education, make clear the direction and purpose of higher education to choose the way and method of education correctly, plan the scientific and effective educational reform plan, and make the development of high sports education more effective. In addition, at the present stage, in the process of participating in the teaching of physical education, the students' learning pressure is often greater in the course of physical education. Many students will devote more energy to the study of professional courses, which lead to the lack of enough attention and cognition for the study of physical education. Therefore, In the course of the overall teaching activities, the effective coordination between the physical education and the professional courses should be done to alleviate the conflicts and contradictions among them, which is the most important content that must be emphasized in the teaching reform of colleges and universities in the current stage.

\subsection{Reasonably enrich and expand the contents of physical education.}

In the process of sports education innovation, we should also make reasonable innovation and improvement on the current sports education content, give students the full choice of space and rights, so that students themselves have a stronger learning interest. In the past, the content of senior physical education courses in colleges and universities is relatively monotonous, and the number of sports items is less. In the process of actual participation, students' interests are difficult to get effective guarantee. In the process of expanding and enriching the relevant physical education curriculum, we 
should understand the actual needs of students, different methods such as questionnaires can be organized to understand the current situation of some of the more popular sports activities for students. Teachers strive for more knowledge from school resources through communication with schools to better enrich the current sports curriculum system. For example, the increase in boxing, swimming, and badminton and so on, these are all kinds of sports which are more concerned and liked by the young students at present. In the actual physical education, the rational arrangement will cause a movement trend in the student group. Students can also communicate with teachers and others better in their own favorite sports, which also helps to ensure the promotion and development of students' social ability.

\subsection{Improve the evaluation methods of physical education.}

Reasonable evaluation is a key to ensure the effectiveness of physical education work, which should improve the scientificness and rationality of evaluation activities in practical teaching [4]. In the actual evaluation, we should cooperate with the use of diversified evaluation ideas to enrich existing evaluation indicators. In terms of specific evaluations, it should improve the way in which the previous general performance and final performance are jointly assessed, consider more of the students' actual performance in the daily participation process, and pay attention to the students' actual participation in physical fitness, knowledge and values, to ensure they have been effectively increased and improved. Such a more flexible and open evaluation system will help teachers better understand the current students' learning situation, make them aware of their own problems and deficiencies, and better help them achieve self-improvement and promotion.

\section{Summary}

With the overall implementation of the quality education, the innovation of college physical education has been a key issue in various colleges and universities. For the development of the innovation of sports education at the present stage, we should fully understand and identify the needs of the development of Physical Education under the quality education. The development of sports education innovation and reform is a systematic task. We must understand the actual development rules and needs of students, and at the same time adopt a more scientific and innovative concept to rationally reform the content of physical education curriculum at the current stage. Therefore, it should seize the entry point for innovation so that the development of sports education reform and innovation can have a stronger timeliness in order to better promote the effective growth and comprehensive development of college students at this stage.

\section{References}

[1] Zhang Zizheng. Methods of Cultivating Undergraduates' Interest in Physical Exercise in the Background of Quality Education[J]. Contemporary Sports Technology,2016,6(18), p.59

[2] Yang Jinpeng, Wang Wei. Study on the Practice of College Physical Education Reform in the Perspective of Quality Education[J]. Examination Weekly, 2017(3), p.14

[3] Zhang Rong. Analysis of the Choice of Innovation Path for College Physical Education Under the Background of Quality Education[J]. Contemporary Sports Science and Technology, 2015,5(12), p.150

[4] Lian Ye. Research on the Practice of College Physical Education Reform from the Perspective of Quality Education[J]. Heilongjiang Higher Education Research, 2016.6, p.32 